Agronomía Costarricense 34(2): 237-250. ISSN:0377-9424 / 2010

www.mag.go.cr/rev_agr/index.html www.cia.ucr.ac.cr

\title{
USO DEL INÓCULO MICROBIAL ELABORADO EN FINCA EN ENSILAJE DE MAÍZ (ZEA MAYS). VALOR NUTRICIONAL Y FERMENTATIVO ${ }^{1}$
}

\author{
José Francisco Cubero*, Augusto Rojas*, Rodolfo WingChing ${ }^{2 / *}$
}

Palabras clave: Proteína cruda, fibra detergente neutro, nutrientes digestibles totales, $\mathrm{pH}$.

Keywords: Crude protein, neutral detergen fiber, digestibility, total digestibility nutrient, $\mathrm{pH}$.

Recibido: $13 / 04 / 10$

\section{RESUMEN}

Se evaluó el efecto de 3 niveles de inóculo microbial producido en finca $\left(0,5,1,0\right.$ y $1,51 . \mathrm{t}^{-1}$ de MF) y un nivel de $0,5 \mathrm{~kg} \cdot \mathrm{t}^{-1} \mathrm{MF}$ de inóculo comercial (CEN-Sile $\left.{ }^{\circledR}\right)$ sobre las características nutricionales y fermentativas del ensilaje de maíz híbrido (Cristiani Burkard@) cosechado a 90 días. Además se evaluó un ensilaje sin la aplicación de inóculo microbial. Para tal fin, se elaboró microsilos de $1,0 \mathrm{~kg}$ de peso fresco en bolsas de polietileno transparente selladas al vacío, las cuales se abrieron al cabo de 70 días de fermentación. En el material antes de ensilar se nota una reducción en el contenido de materia seca (MS), fibra detergente neutro (FDN) y fibra detergente ácida (FDA) conforme se aplica el inóculo, no así en el contenido de proteína cruda (PC). La aplicación de los inóculos microbiales mejoró en promedio en el material ensilado los contenidos de PC, cenizas y extracto etéreo (EE), pero presentó un efecto negativo sobre la MS, la FDN, la FDA, la lignina, la digestibilidad in vitro de la materia seca (DIVMS) y la densidad energética. El ensilaje sin la aplicación de inóculos microbiales presentó los valores mejores en el pH, en la capacidad buffer y en el nivel de nitrógeno amoniacal. El contenido de nutrientes

Este trabajo forma parte de la tesis de licenciatura del primer autor en Ingeniería Agronómica con énfasis en Zootecnia. Escuela de Zootecnia. Facultad de Ciencias Agroalimentarias. Universidad de Costa Rica. San José, Costa Rica.
Aprobado: 25/10/10 
digestibles totales (NDT), la energía digestible y metabolizable, la energía neta de mantenimiento, de ganancia y lactancia fluctuaron entre 57,6566,80\%, 2,54-2,95 Mcal.kg ${ }^{-1}$, 2,08-2,42 Mcal. $\mathrm{kg}^{-1}, 1,23-1,53$ Mcal.kg-1 $, 0,66-0,94$ Mcal.kg-1 y 1,29-1,52 Mcal. $\mathrm{kg}^{-1}$, respectivamente. La aplicación del inóculo microbial no mostró un efecto sustancial sobre las características fermentativas y nutricionales en el ensilaje de maíz, por lo cual se podría recomendar el empleo de este tipo de biotecnologías en forrajes verdes que presentes limitaciones en su proceso fermentativo, como las leguminosas y las gramíneas.

\section{INTRODUCCIÓN}

La conservación de los forrajes, mediante la técnica del ensilaje, surge como una opción viable por su utilidad y fácil implementación por parte de los productores. Esta alternativa asegura la disponibilidad del recurso forrajero durante todo el año en sistemas de producción de rumiantes, debido a que es aplicable a diversos materiales vegetativos que se obtienen en el trópico (Titterton y Bareeba 2001).

En condiciones tropicales, el cultivo de maíz se considera la primera opción para ensilar, debido a su capacidad de adaptación como cultivo a diferentes latitudes, su ciclo de cosecha, entre 80 y 90 días (grano desarrollado en estado pastoso), producciones de forraje verde entre 30 a $50 \mathrm{t}$ materia verde.ha ${ }^{-1}$, alta concentración de carbohidratos fermentables (5 a 20\% MS), baja capacidad alcalinizante y la presencia de una abundante flora natural de microorganismos productores de ácido láctico (Manchin 2001). Además, desde el punto de vista nutricional, el aporte de una alta concentración energética $\left(1,49\right.$ Mcal $\mathrm{EN}_{\mathrm{L}} \cdot \mathrm{kg}^{-1}$ MS) y como limitante, el suministro de cantidades bajas de proteína lo que representa alrededor de un 7\% MS (Abdelhadi 2007).

Se debe considerar que el material ensilado no es de mejor calidad nutricional que el material del cual se origina, debido a que se utiliza como maintenance net energy, growth net energy and lactation net energy fluctuated between 57.65$66.80 \%, 2.54-2.95 \mathrm{Mcal}^{\mathrm{kg}}{ }^{-1}, 2.08-2.42 \mathrm{Mcal}$. $\mathrm{kg}^{-1}, 1.23-1.53$ Mcal.kg ${ }^{-1}, 0.66-0.94$ Mcal. $\mathrm{kg}^{-1}$ and 1.29-1.52 Mcal.kg-1 ${ }^{-1}$, respectively. Microbial additive application did not show a substantial effect on the fermentative characteristics and nutritional value in the corn silage, so this type of biotechnologies could be recommended in green forages with fermentative process limitations, such as leguminous and grass plants.

una técnica para conservar y no para mejorar el material vegetativo empleado (Stefanie et al. 2001), de ahí, que el uso de aditivos se convierte en una alternativa para optimizar el proceso, para asegurar la conservación del material y en algunos casos, incrementar el valor nutricional (Jaster 1995). Comercialmente existen 200 productos, entre químicos y biológicos, empleados como aditivos para mejorar el proceso en los ensilajes (Mahanna 1993). La escogencia del aditivo dependerá del modo de actuar de su ingrediente activo, la efectividad general, el tipo de forraje, facilidad para su manejo, aplicación, precio y su disponibilidad.

En Costa Rica, la aplicación de inóculos bacteriales elaborados en finca como comerciales durante la elaboración del ensilaje es una actividad empleada por la mayoría de productores. En el caso de los inóculos producidos en finca de forma artesanal, preocupa el impacto que estos puedan tener en el proceso y en el producto final, debido a que en su elaboración no presentan controles de calidad que garanticen las poblaciones de microorganismos benéficos para el proceso fermentativo. Es por lo anterior, que el objetivo de este trabajo fue evaluar y comparar los efectos de la aplicación de niveles crecientes de un inóculo microbial producido en finca y uno comercial, sobre las características fermentativas y nutricionales del ensilaje de maíz. 


\section{MATERIALES Y MÉTODOS}

Localización de la investigación. La obtención del inóculo microbial producido en finca, la cosecha del material vegetativo de maíz, como la elaboración de los microsilos se realizo en el distrito de Río Cuarto de Grecia, Alajuela. Región localizada entre $10^{\circ} 20^{\prime} 3^{\prime \prime}$ latitud norte y $84^{\circ} 13^{\prime} 15^{\prime \prime}$ longitud oeste, con una altitud promedio de $999 \mathrm{msnm}$, temperatura ambiental entre los 17,5 y $\operatorname{los} 22,5^{\circ} \mathrm{C}$ y una precipitación pluvial fluctuante entre 3500 a $4000 \mathrm{~mm}$ por año. La conservación de los microsilos durante el periodo de fermentación de 70 días se realizó en estantería bajo condiciones ambientales, al igual que los análisis de laboratorio para determinar la composición nutricional y el proceso fermentativo, ambas actividades, se realizaron en la Sede Rodrigo Facio de la Universidad de Costa Rica, situada en San Pedro de Montes de Oca, San José, respectivamente, en la Escuela de Zootecnia y el Laboratorio de Bromatología del Centro de Investigación en Nutrición Animal (CINA).

Elaboración del inóculo en finca. En un recipiente con tapa, con capacidad de 201 , se mezcló un litro de microorganismos eficientes (EM®), compuesto de una población de Lactobacillus casei $\left(10^{4}\right.$ UFC.ml-1), Rhodopseudomonas polistris $\left(10^{3} \mathrm{UFC}_{\mathrm{ml}}^{-1}\right)$ y Saccharomyces cerevisiae $\left(10^{3}{\text { UFC. } l^{-1}}^{-1}\right), 3,781$ de melaza; se aforo con agua y se dejó fermentar por 10 días (producto activado). En el momento que se empleó, se agregó 7,56 1 de una relación 1:1 del producto activado con melaza a un estañon de 2001 , el cual se lleno con agua hasta alcanzar su capacidad e inmediatamente se utilizó. Al momento de ser empleado se desconoce la población de microorganismos y su concentración tanto en la mezcla final como en el producto activado. Por tal motivo, se considera como población microbial base del inóculo elaborado en finca, la descrita en el análisis de garantía de los EM®.

Material vegetativo. Se utilizó follaje de maíz híbrido (Cristiani Burkard®), el cual fue cosechado a 90 días después de la siembra mediante una cosechadora de 2 surcos (John Dear®), simultáneamente el material se pico a un tamaño de partícula de $2,5 \mathrm{~cm}$.

Preparación de los microsilos y toma de la muestra. Se elaboraron microsilos de $1,0 \mathrm{~kg}$ de peso fresco, en bolsas de polietileno transparente $(0,063 \mathrm{~mm})$ selladas al vacío con ayuda de una bomba. Para el llenado de los microsilos se emplearon porciones aleatorias de material. Tal material se preparo, según el tratamiento, con niveles de inóculo microbial producido en finca de $0,5,1,0$ y $1,51 . t^{-1}$ de follaje fresco, un inóculo comercial a razón de $0,5 \mathrm{~kg} . \mathrm{t}^{-1}$ de material fresco, según especificaciones del fabricante (CEN-Sile $\left.{ }^{\circledR}\right)$ y un control (ausencia de inóculo microbial). En el caso del aditivo comercial, este está constituido por bacterias lácticas a razón de $1 \times 10^{11}$ UFC. $\mathrm{kg}^{-1}$ (Lactobacillos acidophilus, Enterococcus faecium, Lactobacillos plantarum y Pediococcus acidilactici). Para cada tratamiento se elaboró 5 repeticiones, para un total de 25 microsilos.

Al inicio del experimento, se tomó una muestra compuesta del material fresco para cada tratamiento, esta muestra fue utilizada como referencia (día cero), previo al proceso de ensilaje. Al finalizar el periodo de fermentación, se procedió a abrir los microsilos y separar las partes que se encontraron en estado de descomposición, posteriormente, se separó el material en 2 muestras, las cuales se emplearon en la caracterización fermentativa y nutricional del material ensilado, respectivamente.

Análisis de laboratorio. Las muestras recolectadas antes y después del proceso fermentativo, se le analizaron el contenido de materia seca (MS), en estufa a $60^{\circ} \mathrm{C}$ durante 48 horas, proteína cruda (PC) y cenizas (Ce) según la AOAC (1991), fibra detergente neutro (FDN), lignina y fibra detergente ácido (FDA) (Van Soest y Robertson 1985). El contenido de extracto etéreo (EE), nitrógeno amoniacal ( $\mathrm{N}$-amoniacal.Ntotal $\left.^{-1}\right)$, carbohidratos no fibrosos (CNF) y el $\mathrm{pH}$, se determinaron únicamente en las muestras 
obtenidas después del proceso fermentativo, mediante los procedimientos descritos por la AOAC (1991) y Rojas (1985), respectivamente. La capacidad buffer del material después de ensilar se determinó mediante la metodología descrita por Mc Donald (1981). Las estimaciones de nutrientes digestibles totales a una vez mantenimiento $\left(\mathrm{NDT}_{1 \mathrm{X}}\right.$ ) (Weiss 1999) y de energía digestible, metabolizable, neta de mantenimiento, neta de ganancia y neta de lactación (Linn 2001) se le realizaron a los tratamientos que presentaron la calidad nutricional máxima y mínima en conjunto con los parámetros fermentativos. Para tal fin, se considero al tratamiento con calidad nutricional máxima, al que presentó mayor contenido de PC y digestibilidad in vitro de la MS, como un valor menor en su concentración de FDN, FDA, lignina y en su valor de $\mathrm{pH}$.

Diseño experimental. Se utilizó un modelo irrestricto al azar, con 5 tratamientos y 5 repeticiones para evaluar el efecto de la aplicación de 5 niveles de inóculos en ensilajes, sobre las variables bromatológicas y fermentativas del ensilaje de maíz. El análisis de varianza se realizó mediante el modelo ANOVA de SAS. En el caso del análisis de regresión, para definir las tendencias obtenidas en relación a la aplicación de niveles crecientes del inóculo elaborado en finca $\left(0,0,5,1\right.$ y $\left.1,51 . t^{-1}\right)$, se utilizó el programa de
Microsoft Office Excel de Windows 2003. Para la determinación de diferencias estadísticas entre medias se aplicó la prueba de Waller mediante el programa SAS (2003).

\section{RESULTADOS Y DISCUSIÓN}

\section{Valoración nutricional del material antes de ensilar}

Se observó una disminución sobre el contenido de MS, causada por la aplicación del inóculo microbial producido en finca, así como una tendencia a reducir el contenido de FDN y FDA conforme se incrementa la dosis del mismo, lo cual puede atribuirse al muestreo o al aporte de humedad del tratamiento, lo que provoca un efecto de dilución (Cuadro 1). En general, la aplicación del inóculo comercial o producido en finca disminuye el contenido de MS en relación al tratamiento sin aditivo. Caso contrario, se presenta para el contenido de PC un incremento conforme aumenta la dosis del inóculo, independientemente del tipo de inóculo, situación que podría atribuirse al nitrógeno que podrían aportar los microorganismos. Con respecto, el porcentaje de cenizas no presenta una tendencia definida en función de la aplicación del inóculo, por lo que no se aprecia un efecto de los tratamientos sobre esta variable.

Cuadro 1. Características nutricionales del forraje de maíz, con 3 niveles de inóculos microbiales producidos en finca, un inóculo comercial y sin la aplicación del inóculo microbial.*

\begin{tabular}{|c|c|c|c|c|c|}
\hline \multirow{3}{*}{ Indicador } & \multicolumn{5}{|c|}{ Inóculo } \\
\hline & \multirow[t]{2}{*}{ Sin inóculo } & \multirow{2}{*}{$\begin{array}{c}\text { Comercial }\left(\mathrm{kg} \cdot \mathrm{t}^{-1}\right) \\
0,5\end{array}$} & \multicolumn{3}{|c|}{ Elaborado en finca $\left(1 . \mathrm{t}^{-1}\right)$} \\
\hline & & & 0,5 & 1,0 & 1,5 \\
\hline Materia seca (\%) & 18,30 & 17,90 & 17,90 & 18,80 & 18,20 \\
\hline Proteína cruda (\% MS) & 8,84 & 9,84 & 8,79 & 9,35 & 9,42 \\
\hline Fibra detergente neutra (\% MS) & 67,3 & 65,9 & 67,8 & 62,1 & 61,8 \\
\hline Fibra detergente ácida(\% MS) & 35,6 & 34,5 & 35,9 & 32,0 & 31,6 \\
\hline Cenizas (\% MS) & 5,69 & 5,37 & 5,53 & 5,62 & 5,24 \\
\hline
\end{tabular}

\footnotetext{
* Datos correspondientes al análisis de una muestra compuesta.
} 
Sobre el contenido de MS, León y Montenegro (2001) y González (1988) citan valores para forraje de planta entera de maíz fresco por encima de lo encontrado en esta investigación $(32,02-34,44 \%$ y $22,48-28,28 \%$, respectivamente), esta diferencia en cuanto al contenido de este indicador se podría atribuir a la edad de cosecha, condiciones ambientales durante la cosecha y a la variedad de maíz empleado.

El contenido de PC obtenido en esta investigación, excede lo indicado por González (1988) y Johnson et al. (2002), quienes señalan promedios de 7,0 y $8,4 \%$ PC para material fresco de forraje de maíz híbrido 3845 y Quanta, cosechadas entre 90 y 110 días, respectivamente. En cambio, los datos obtenidos en esta investigación, coinciden con la información descrita por Forouzmand et al. (2005), para las variedades SC 704TM y TWC 647TM, por Chen et al. (1994), por Ranjit y Kung (2000) con porcentajes de $8,42,9,34,9,33$ y $9,70 \%$, respectivamente.

Las concentraciones de FDN y FDA para el tratamiento sin aditivos, se encuentran por encima de los valores informados por Forouzmand et al. (2005), Johnson et al. (2002) y Neumann et al.
(2007), en donde mencionan rangos promedios de concentración entre 44,1 a $55,88 \%$ y de 23 a $28,4 \%$ para la FDN y la FDA, respectivamente. Las diferencias encontradas en estos indicadores se pueden atribuir a la edad de cosecha del forraje, condiciones ambientales y proporción de número de mazorcas y follaje al momento de la cosecha y a la variedad del maíz utilizado.

\section{Valoración nutricional del material después del periodo fermentativo}

Materia seca total (MST). Se obtuvo diferencias por efecto de la aplicación del inóculo en los materiales ensilados $(\mathrm{p}<0,0001)$ (Cuadro 2), se cuantifico un comportamiento cuadrático $\left(\mathrm{R}^{2}=0,60\right)$ en relación con la dosis creciente del inóculo producido en finca. Al comparar el tratamiento de inóculo comercial (CEN-Sile $\left.{ }^{\circledR}\right)$ con el tratamiento sin aditivo no se determinó diferencia significativa, caso contrario, al confrontar los tratamientos con inóculo producido en finca, el grupo control y el inóculo comercial $(\mathrm{p}<0,0001)$ (Cuadro 2). El contenido de MST mayor se obtuvo

Cuadro 2. Características fermentativas y nutricionales del ensilaje de maíz con 3 niveles de inóculos microbiales producidos en finca, un nivel de inóculo comercial y sin la aplicación de inóculo microbial.

\begin{tabular}{|c|c|c|c|c|c|}
\hline \multirow{3}{*}{ Indicador } & \multicolumn{5}{|c|}{ Inóculo aplicado } \\
\hline & \multirow[t]{2}{*}{ Sin inóculo } & \multirow{2}{*}{$\begin{array}{c}\text { Comercial }\left(\mathrm{kg} \cdot \mathrm{t}^{-1}\right) \\
\quad 0,5\end{array}$} & \multicolumn{3}{|c|}{ Elaborado en finca $\left(1 . t^{-1}\right)$} \\
\hline & & & 0,5 & 1,0 & 1,5 \\
\hline \multicolumn{6}{|c|}{ Características nutricionales $^{1}$} \\
\hline Materia seca total & $15,71_{\mathrm{a}}$ & $15,50_{\mathrm{a}}$ & $14,63_{\mathrm{c}}$ & $15,14_{b}$ & $15,07_{b}$ \\
\hline Proteína cruda & $8,54_{\mathrm{ab}}$ & $8,87_{\mathrm{a}}$ & $8,70_{\mathrm{ab}}$ & $8,38_{\mathrm{b}}$ & 8,90 a \\
\hline Fibra detergente neutra & $58,64_{b}$ & $59,74_{b}$ & $60,28_{b}$ & $65,74_{\mathrm{a}}$ & $66,48_{\mathrm{a}}$ \\
\hline Fibra detergente ácida & $37,00_{c}$ & $37,30_{\mathrm{bc}}$ & $38,02_{\mathrm{abc}}$ & $39,92_{\mathrm{ab}}$ & $40,30_{\mathrm{a}}$ \\
\hline Lignina & $2,32_{c}$ & $2,36_{c}$ & $4,46_{b}$ & $5,18_{\mathrm{a}}$ & $4,98_{\mathrm{ab}}$ \\
\hline Cenizas & 5,63 & 5,81 & 5,77 & 5,61 & 5,77 \\
\hline Extracto etéreo & 1,61 & 1,73 & 1,83 & 1,79 & 1,72 \\
\hline Carbohidratos no fibrosos & $25,588_{a}$ & $23,85_{\mathrm{a}}$ & $23,42_{\mathrm{a}}$ & $18,48_{\mathrm{b}}$ & $17,13_{\mathrm{b}}$ \\
\hline Digestibilidad in vitro de la MS & $70,14_{a}$ & $67,58_{\mathrm{ab}}$ & $67,92_{\mathrm{ab}}$ & $68,00_{\mathrm{ab}}$ & $63,08_{b}$ \\
\hline \multicolumn{6}{|c|}{ Características fermentativas } \\
\hline $\mathrm{pH}$ & $3,49 \mathrm{~b}$ & $3,67 \mathrm{a}$ & 3,67 a & $3,47_{b}$ & $3,45_{b}$ \\
\hline Capacidad buffer (meq NaOH.100 g-1 de MS) & $102,4_{c}$ & $98,7_{\mathrm{c}}$ & $117,1_{\mathrm{b}}$ & $130,5_{\mathrm{a}}$ & $132,2 \mathrm{a}$ \\
\hline Nitrógeno amoniacal (N-amoniacal.N-total ${ }^{-1}$ ) & $6,01_{c}$ & $6,65_{b}$ & $8,23_{\mathrm{a}}$ & $6,99_{b}$ & $7,00_{b}$ \\
\hline
\end{tabular}

1 Datos expresados como porcentaje de la materia seca (\% MS). Promedio de 5 muestras.

$\mathrm{a}, \mathrm{b}, \mathrm{c} \quad$ valores con letras diferente en la misma fila difieren entre sí, según la prueba de Waller $(\mathrm{p}<0,05)$. 
en el tratamiento sin aditivo, mientras que, el tratamiento con $0,51 . \mathrm{t}^{-1}$ de inóculo producido en finca presentó el contenido menor $(15,71 \% \pm 0,11$ contra $14,63 \% \pm 0,31) \quad(\mathrm{p}<0,0001)$. Lo anterior indica que el inóculo microbial producido en finca tiende a disminuir la MST en el ensilado de maíz mientras que el inóculo comercial no la afecta. Esta disminución puede ser causada por la o las poblaciones de microorganismos presentes en los tratamientos con inóculos producidos en finca, que descomponen una mayor proporción del material vegetativo que la población del inóculo comercial.

Los valores de MST obtenidos en esta investigación, se encuentran por debajo de los valores indicados por Kung et al. (2008) de $32,9-33,3 \%$, Kleinschmit y Kung (2006) de $30,70 \% \pm 1,15$ y Tobía et al. (2007) de $24,5 \%$ para ensilajes de maíz sin inóculo. Este comportamiento podría ser explicado por efecto del microsilo empleado, el cual no permite la salida de efluentes y al procedimiento empleado para la toma de la muestra homogénea, donde al momento de la apertura, se mezcló la parte superior del material con la parte inferior. Según Boschini y Elizondo (2003) los porcentajes obtenidos de MST clasifican a estos materiales fermentados como ensilajes con humedad alta, independientemente del tratamiento empleado, por lo que estos ensilados no favorecen al consumo de MST en animales, cuya dieta se suplementa con este tipo de material.

Hag et al. (1982) informan resultados similares al comparar ensilajes de maíz con y sin inóculo (Lactobacillus buchneri), donde encuentran una disminución en la materia seca conforme se aplica el inóculo, donde se pasa de 37\% MS en el tratamiento sin inóculo a $35,90 \%$ MS en la dosis del inóculo bacterial superior (50 ppm), lo cual lo atribuyen al aporte de humedad presente en el material a ensilar, debido a que entre mayor sea el contenido de humedad menor será el porcentaje de materia seca presente al final del proceso fermentativo. Similar resultado obtienen Kung et al. (1993) al evaluar el contenido de materia seca al utilizar el aditivo microbial Ecosyl®
(Lactobacillus plantarum) en una dosis de $1 \times 10^{6}$ UFC en ensilajes de maíz (32,9 y 39,8\% para tratamientos con inóculo contra 34,7 y 39,9\% para el control, respectivamente).

Proteína cruda (PC). Se determinó una tendencia cuadrática $\left(R^{2}=0,41\right)$ en el contenido de PC según la dosis del inóculo producido en finca $(\mathrm{p}<0,05)$ (Cuadro 2). Los mayores contenidos de este indicador, se cuantificó en el ensilaje con adición de 1,5 $1 . \mathrm{t}^{-1}$ de inóculo elaborado en finca, aunque no difiere significativamente del ensilaje con aplicación del CEN-Sile $®$, 0,5 1.t $\mathrm{t}^{-1}$ inóculo elaborado en finca y el tratamiento sin aditivos.

La concentración de PC descritas por Eun et al. (2007), Ferreira y Mertens (2005) y Forouzmand et al. (2005) para ensilajes de maíz sin inóculo, son menores a las determinadas en este trabajo $(6,6 \% ; 7,8 \% \pm 1,4 ;$ y 7,55-9,04\%, respectivamente) pero similares a las descritas por Ballard et al. (2001) para la variedad Cargill, Johnson et al. (2002) y Tobía et al. (2007) $(8,7 \% ; 8,0-8,8 \%$ y $8,9 \%$, respectivamente). Similar comportamiento se obtuvo en el contenido de PC al comparar los valores de los tratamientos con aditivos microbiales con trabajos similares en ensilajes de maíz, como los informados por Wohlt (1989), Ranjit y Kung (2000) y Kung et al. (1993) $(8,4 \% ; 7,60 \%$; y $7,57-8,51 \%$, respectivamente). Las variaciones de PC, encontradas en la literatura, podría deberse al tipo de variedad de maíz empleado, tamaño de partícula (Neuman et al. 2007), tipo de inóculo aplicado, edad de cosecha y las condiciones al momento de la cosecha, condiciones que afectan el contenido de PC (WingChing-Jones 2006).

Fibra detergente neutro (FDN). Se presentó diferencia significativa entre aplicar o no el aditivo $(p<0,0033)$. La aplicación del aditivo microbial aumenta la concentración de FDN según la dosis del inóculo, sea este comercial o elaborado en finca, comportamiento que se podría explicar por la utilización de otros compuestos de carbono más disponibles por las poblaciones de microorganismos presentes en el inóculo, lo que incrementa la preservación de la FDN (Cuadro 2). 
Así, el mayor contenido de esta fracción fibrosa, se determinó en los tratamientos con dosis de 1 y 1,5 $1 . \mathrm{t}^{-1}$ de inóculo microbial, mientras que, el tratamiento con inóculo comercial y el control (Sin inóculo) presentan los menores valores para esta fracción (Cuadro 2). Este aumento en el contenido de FDN podría reducir el consumo de materia seca, por un llenado físico de la cavidad ruminal, por consiguiente, una reducción en el aporte de nutrimentos al sistema (Holland et al. 1995).

Estudios en ensilajes de maíz sin inóculo microbial indican un valor para esta fracción de la pared celular de 43,8\% (Eun et al. 2007), mientras que otros como los descritos por Kung et al. (1993) y McDonald (1981) mencionan valores de $44,1 \%$ y de $41,3 \%$, respectivamente. Estos mismos autores mencionan un rango entre 43,1 y $43,8 \%$ para esta fracción en ensilajes inoculados; similar resultado describen Ranjit y Kung (2000) $(44,2 \%)$. En cambio, Forouzmand et al. (2005) mencionan valores de FDN más altos para el ensilaje de maíz inoculado (49,1-49,62\%), pero aun así, valores menores a los obtenidos en este estudio. Tal situación podría ser explicada a la edad de cosecha, tamaño de partícula (Neuman et al. 2007), condiciones ambientales y a la relación existente entre número de mazorcas y follaje al momento de la cosecha y a la variedad de maíz utilizado.

Fibra detergente ácida (FDA). La adición del aditivo microbial afecta el contenido de FDA ( $\mathrm{p}<0,0380)$ (Cuadro 2), se determino una relación directa y proporcional de esta variable al aumento en la dosis del inóculo producido en finca. En cambio, al comparar el tratamiento sin aditivo con el inóculo comercial, no se determinó diferencia significativa entre ellos $(\mathrm{p}>0,05)$. El tratamiento con la dosis mayor de inóculo producido en finca obtuvo el porcentaje de FDA más alto, pero no varió con relación a los otros niveles ( $p>0,05)$, mientras que, el tratamiento control presentó la concentración menor $(40,30 \% \pm 1,18$ contra $37,00 \pm 0,48 \%$ respectivamente) $(\mathrm{p}<0,0380)$. Este efecto de la aplicación del inóculo sobre el contenido de FDA en el material ensilado, determinado en este trabajo, es similar a lo informado por Kung et al. (1993), Wohlt (1989) y Luther (1986), los cuales atribuyen dicho aumento a un efecto en la estabilidad del material fermentado, que disminuye la descomposición de esta fracción de la pared celular, lo que provoca que otra fracción disminuya, por la utilización eficiente de componentes más disponibles (no fibrosos) presentes en el material durante el proceso fermentativo. Estos porcentajes de FDA generan una reducción en el aporte energético de la dieta de los animales, debido, a que esta fracción se relaciona con la digestibilidad del material, razón por la cual ensilajes de maíz con inóculo producido en finca, podrían tener un efecto negativo en la productividad de animales que son alimentados con este tipo de material (Holland et al. 1995).

Lignina. Se observó un comportamiento cuadrático $\left(\mathrm{R}^{2}=0,99\right)$ con relación a la aplicación de niveles crecientes de inóculo microbial elaborado en finca (Cuadro 2). El porcentaje de lignina menor lo presentó el tratamiento sin aditivos $(2,32 \%)$ y el contenido mayor en los tratamientos con dosis de 1,0 y $1,51 . \mathrm{t}^{-1}$ inóculo microbial elaborado en finca. Entre el inóculo comercial y el producido en finca se obtuvo diferencias significativas $(\mathrm{p}<0,0001)$, pero no así, entre el tratamiento con inóculo comercial y el ensilaje sin aditivos. Este incremento en el contenido de lignina al emplear inóculo elaborado en finca, podría estar relacionado al incremento de la FDA descrito anteriormente. Esta fracción de FDA está constituida por la pared celular primaria que contiene celulosa, hemicelulosa y lignina, entre otras. El incremento en lignina provoca una disminución de la digestibilidad del material ensilado lo cual va en detrimento de la calidad nutricional de dicho material fermentado (Holland et al. 1995).

Cenizas. Los contenidos de ceniza encontrados en esta investigación, no difieren significativamente entre tratamientos. Resultado similar obtienen Sibanda et al. (1997) de 5,2\% 
en ensilados de maíz mezclados con leguminosa (mezclas de $85 \%$ y $15 \%$, respectivamente). Para Hoffman (2005), contenidos de cenizas mayores a $10 \%$ en un ensilaje de maíz, son indicativos de contaminación por suelo en la muestra analizada. Los valores determinados en este trabajo coinciden con lo citado por McDonald (1981) y Johnson et al. (2002) quienes mencionan porcentajes de cenizas de $5,5 \%$ y $4,5-4,7 \%$, respectivamente, para ensilajes de maíz con inóculo, pero presentan concentraciones mayores a lo citado por Kung et al. (2008) quienes indican valores de $3,48-3,78 \%$ para el mismo material fermentado. Variables como la variedad, la frecuencia de corta, la deshidratación y la inclusión de aditivos podrían afectar el contenido de cenizas en los materiales ensilados (WingChing-Jones 2006).

Extracto etéreo (EE). La variación en el contenido de EE no fue significativa en esta investigación (Cuadro 2). A pesar de lo anterior, los porcentajes de EE fluctúan entre 1,61 y 1,83\%, valores que están dentro de los rangos normales para este tipo de material fermentado (Huffman y Duncan 1955). Tal comportamiento, podría deberse a que el inóculo no aporta cantidades suficientes de lípidos, vitaminas liposolubles, entre otros, que puedan incrementar dicho indicador. Además, los valores tan bajos determinados en esta investigación, hacen considerar al ensilaje de maíz una mala fuente de energía a partir de lípidos, pero es importante considerar que el nivel máximo de EE en la dietas de vacas lecheras no debe ser mayor al 5\% (Palmquist y Jenkins 1980).

Carbohidratos no fibrosos (CNF). La aplicación del inóculo microbial afecto esta fracción $(\mathrm{p}<0,05)$. Se nota que a niveles mayores de 1 1.t $\mathrm{t}^{-1}$ de inóculo elaborado en finca (Cuadro 2), se obtiene un valor de CNF menor en el material ensilado, lo cual podría indicar una participación mayor de los componentes de esta fracción durante el proceso fermentativo. Trabajos publicados por Ferreira y Mertens (2005) indican valores de CNF en ensilaje de maíz superiores a los informados en este trabajo $(41,6 \pm 7,1 \%)$, tal situación podría deberse a la variedad empleada, la edad de cosecha y a la cantidad de grano en el momento de la cosecha, variable que influye el contenido de CNF (Cabral et al. 2002). En cambio, los valores de CNF informados por Diesel et al. (2007) presentan un rango similar $(20,9$ y $33,7 \%)$ a los obtenidos en este trabajo (Cuadro 2). Estos valores de CNF superan en promedio en 10 unidades porcentuales el contenido de CNF de forrajes tropicales empleados en sistemas de producción de leche (Sánchez y Soto 1996). Estos autores sugieren la necesidad de mejorar este componente en la dieta de animales rumiantes alimentados a base de forraje, de tal manera que el ensilaje de maíz podría ser considerado para este propósito.

Digestibilidad in vitro de la materia seca (DIVMS). No se detectaron efectos negativos del uso del inóculo sobre la DIVMS excepto cuando se aplicó a 1,5 1.t $\mathrm{t}^{-1}$ de inóculo elaborado en finca. También se determinó que no existe un efecto en la DIVMS del ensilado según el tipo de inóculo empleado. McDonald (1981) menciona valores para DIVMS del ensilaje de maíz (variedad Canadian) de $75 \%$ como mínimo y $86 \%$ como máximo, rango mayor al encontrado en este trabajo (63-70\%), lo cual puede atribuirse al híbrido empleado, a la edad de corta y al período de fermentación. Mientras que, los resultados informados por Tobía et al. (2007) en ensilaje de maíz en condiciones tropicales concuerdan con lo obtenido en esta investigación. Esta disminución en la DIVMS del ensilaje por la adición de inóculo microbial se asocia a la relación inversa que existe con la fracción de la pared celular, ya que conforme aumentan los contenidos de FDA y lignina, disminuye la digestibilidad del material fermentado.

Según Quirós (1992), la DIVMS del ensilaje de maíz dependerá de la digestibilidad del forraje en pie, además, las posibles variaciones en este indicador se deben a un desequilibrio en la proporción de los componentes estructurales que permanecen inalterados, durante el proceso fermentativo, con respecto a la transformación de la fracción digestible del componente celular. 
Coinciden Baxter et al. (1980) y Di Marco et al. (2005) al citar porcentajes de DIVMS menores para los forrajes ensilados cuando se comparan con los forrajes frescos y se lo atribuyen a las pérdidas inevitables, de diferentes fracciones del material, que ocurren durante la fermentación y la conversión de componentes químicos de la planta en otros menos provechosos.

Contenido energético. Los valores determinados en esta investigación (Cuadro 3), demuestran que el ensilado sin aditivo, considerado el mejor tratamiento, presentó una densidad energética mayor al 13,70, 13,90, $14,05,19,61,29,79$ y $15,13 \%$ a los valores obtenidos por el tratamiento que se le aplicó 1,5 $1 . \mathrm{t}^{-1}$ de inóculo producido en finca (tratamiento peor), para el contenido de $\mathrm{NDT}_{1 \mathrm{X}}$, la energía digestible, metabolizable, neta de mantenimiento, neta de ganancia y neta de lactación, respectivamente. Huffman y Duncan (1955) mencionan valores de NDT de 62,68 y 66,56\%, para ensilajes de maíz de la variedad Eureka y Ohio M15, cosechados a 90 y 70 días de edad, respectivamente, valor inferior al obtenido en esta investigación para el tratamiento mejor. En cambio, Holland et al. (1995) indican un contenido de $70 \%$ de NDT para ensilajes de maíz con un tiempo de cosecha de 90 días de edad, valor que supera en 3,2 y 12,35 unidades porcentuales el NDT obtenido en esta investigación para el mejor y peor tratamiento, respectivamente. Lo anterior, indica que la adición del inóculo elaborado en finca en dosis altas, no mejora los valores de ED, EM, $\mathrm{EN}_{\mathrm{M}}, \mathrm{EN}_{\mathrm{G}}$ y $\mathrm{EN}_{\mathrm{L}}$ para ensilajes de maíz, por su efecto negativo sobre el contenido de NDT.

Esta diferencia de $9,15 \%$ de NDT entre el tratamiento mejor y peor, se podría relacionar a la alta correlación descrita por Cabral et al. (2002) entre NDT y contenido de FDN, debido a que el ensilaje con adición de 1,5 1.t. ${ }^{-1}$ presentó los contenidos de FDA, FDN y lignina más altos. Esta situación, compromete el consumo de energía, lo que podría reducir el crecimiento corporal, la producción de leche o carne y las características bromatológicas de la leche y de la carne. Además podría, deteriora los índices reproductivos y la salud de los animales en periodos prolongados de uso (Tobía et al. 2007).

Cuadro 3. Contenido de nutrientes digestibles totales (1X) y el fraccionamiento de la energía (del ensilaje de maíz) con adición de $1,51 . \mathrm{t}^{-1}$ de inóculo microbial producido en finca y sin aplicación de inóculo microbial.*

\begin{tabular}{lcc}
\hline & \multicolumn{2}{c}{ Ensilaje de maíz } \\
\cline { 2 - 3 } Fracción energética & Sin inóculo microbial & $1,51 . \mathrm{t}^{-1}$ \\
Mcal.kg & & inóculo microbial $^{-1}$ de MS \\
Nutrientes digestibles totales (\%) & $66,80_{\mathrm{a}}$ & $57,65_{\mathrm{b}}$ \\
Energía digestible & $2,95_{\mathrm{a}}$ & $2,54_{\mathrm{b}}$ \\
Energía metabolizable & $2,42_{\mathrm{a}}$ & $2,08_{\mathrm{b}}$ \\
Energía neta de mantenimiento & $1,53_{\mathrm{a}}$ & $1,23_{\mathrm{b}}$ \\
Energía neta de ganancia & $0,94_{\mathrm{a}}$ & $0,66_{\mathrm{b}}$ \\
Energía neta de lactación & $1,52_{\mathrm{a}}$ & $1,29_{\mathrm{b}}$ \\
\hline
\end{tabular}

*Valor promedio de 5 muestras.

a, b, c valores con letras diferente en la misma fila difieren entre sí, según la prueba de Waller ( $\mathrm{p}<0,05)$.

\section{Valoración fermentativa del material después del periodo fermentativo}

pH. Los valores de $\mathrm{pH}$ obtenidos en cada tratamiento de esta investigación permiten categorizar al material fermentado como un ensilaje bueno (Peña y del Pozo 1992). En el Cuadro 2 , se muestra como los valores de $\mathrm{pH}$ disminuyen conforme se aumentó la aplicación del inóculo producido en finca en el material fermentado 
$(\mathrm{p}<0,002)$. Por otro lado, el tratamiento de 0,5 $1 . \mathrm{t}^{-1}$ de inóculo producido en finca y el inóculo comercial presentan un efecto similar sobre este indicador. Los datos obtenidos en este trabajo, coinciden con lo mencionado por Johnson et al. (2002), Forouzman et al. (2005) y Kleinschmit y Kung (2006), quienes informan en sus trabajos rangos de $\mathrm{pH}$ que fluctúan entre 3,7-4,50 para ensilajes de maíz sin inóculo. Los mismos autores citan rangos de pH para ensilajes de maíz inoculados entre 3,69-4,09 mientras que un único trabajo revisado, cita un valor de $\mathrm{pH}$ para ensilaje de maíz inoculado de 5,48 (Ranjit y Kung 2000).

Los valores de $\mathrm{pH}$ bajos, describen el efecto de la incorporación del inóculo microbial, sea este comercial o no, debido a que propician un proceso fermentativo más intenso, lo que beneficia el proceso de fermentación láctica (Boschini y Elizondo 2003), lo que podría reducir las pérdidas por descomposición anaeróbica y evitar el crecimiento de poblaciones de bacterias no deseadas, cuantificar una menor capacidad buffer en el material ensilado, reducir la concentración de los ácidos acético y butírico, como también, minimizar la destrucción de la proteína del material por fermentaciones clostridiales (Mc Donald 1981).

Paradójicamente ensilajes con un proceso fermentativo adecuado $(\mathrm{pH}<3,9)$ son materiales que presentan problemas de consumo por los animales (Shaver et al. 1984), pues los niveles de pH bajos en los forrajes ensilados se consideran como inhibidor del consumo en los animales. Los valores de $\mathrm{pH}$ obtenidos en esta investigación (3,45 mínimo y 3,67 máximo) se encuentran por debajo del rango de optimización del consumo de ensilaje de maíz $(4,46$ y 5,62) (Shaver et al. 1984), lo cual se podría atribuir al aumento en la proporción de ácido láctico producto a la utilización de inóculo microbial en esta investigación.

Capacidad buffer (CB). La resistencia al cambio en su valor de $\mathrm{pH}$ durante el proceso fermentativo provocado por las características de la planta, se conoce como capacidad buffer o tampón (Otero y Esperance 1994), en esta investigación, este indicador presentó un comportamiento lineal entre la aplicación del inóculo elaborado en finca y la capacidad amortiguadora (Cuadro 2). Se determinó diferencias significativas entre el tratamiento sin aditivos y los 3 niveles de inóculo producido en finca $(\mathrm{p}<0,001)$, no así con el inóculo comercial. Los resultados obtenidos en esta investigación son cercanos a los informados por Chen et al. (1994) para ensilaje de maíz de 89,8 y 91,6 meq NaOH.100 g ${ }^{-1}$ de MS cosechado a los 90 días con inóculo y sin inóculo respectivamente. En cambio, valores menores mencionan McDonald (1981) y Shaver et al. (1984) para el ensilaje de maíz, quienes indican valores de 28,5 y 44,2 meq NaOH.100 $\mathrm{g}^{-1}$ de MS, respectivamente. Tales diferencias pueden deberse tanto a variaciones en el híbrido de maíz, el periodo de fermentación (Johnson et al. 2002), como al método experimental empleado en las diferentes investigaciones, debido a que en algunos casos la muestra es licuada antes de su lectura y para este trabajo, fue macerada (WingChing-Jones 2006).

Concuerdan Giger-Reverdin et al. (2002), Montañez et al. (2006) y Jasaitis et al. (1987), en que, mayor contenido de proteína presente el forraje en fresco, mayor será su CB. Lo anterior, podría explicar los valores de $\mathrm{pH}$ bajos obtenidos en esta investigación, pues al contar el material con bajos niveles de PC $(7,54-8,90)$, aunado a su alta concentración de carbohidratos solubles, implica una $\mathrm{CB}$ baja al inicio del proceso fermentativo. Es importante diferenciar, que la $\mathrm{CB}$ determinada en los materiales ensilados es producto en su mayoría a los ácidos que se forman durante el periodo fermentativo.

Nitrógeno amoniacal $\left(\mathbf{N}-\mathbf{N H}_{3}\right)$. El contenido de $\mathrm{N}-\mathrm{NH}_{3}$ presente en el ensilaje de maíz varió de manera significativa según el nivel de aplicación del inóculo microbial ( $\mathrm{p}<0,0001)$, donde el tratamiento sin aditivos presentó una concentración menor que los tratamientos con aditivo, lo que indica, la poca funcionalidad de los inóculos microbiales en la conservación de la proteína (Cuadro 2). Aunque, se determino variaciones en el contenido de $\mathrm{N}-\mathrm{NH}_{3} \cdot \mathrm{N}$-total ${ }^{-1}$ en los tratamientos evaluados en esta investigación, 
son considerados ensilajes de excelente calidad, debido a que presentan concentraciones menores al 8\%, excepto para el ensilaje con aplicación de $0,51 . \mathrm{t}^{-1}$, el cual se califica como bueno, según parámetros descritos por Peña y del Pozo (1992).

No se determinó diferencias significativas entre los tratamientos con dosis de 1,0 y $1,51 . \mathrm{t}^{-1}$ del inóculo microbial producido en finca y el tratamiento con inóculo comercial, caso contrario, la dosis de $0,51 . t^{-1}$ de inóculo producido en finca, donde se obtuvo la concentración de nitrógeno amoniacal mayor $\left(8,23 \pm 0,84 \% \mathrm{NH}_{3} \cdot \mathrm{N}_{\text {-total }}{ }^{-1}\right)$, lo que supone una transformación de la proteína a formas más solubles.

La formación de $\mathrm{N}_{-} \mathrm{NH}_{3}$ se favorece por la presencia del inóculo, sea este comercial o elaborado en finca, al compararse con el tratamiento sin aditivos, lo cual se puede atribuir al tipo de bacterias presentes en el inóculo, que descomponen la proteína durante el proceso fermentativo. Además, la cantidad de humedad presente durante el proceso fermentativo podría favorecer la producción del $\mathrm{N}_{-} \mathrm{NH}_{3}$ durante el proceso (Kung et al. 1993).

\section{CONCLUSIONES}

La aplicación del inóculo microbial, sea este comercial o producido en finca en esta investigación no mostró un efecto sobre los valores de $\mathrm{pH}$, capacidad amortiguadora, el contenido de nitrógeno amoniacal y los contenidos de MS, PC, FDA, FDN y DIVMS en el ensilaje de maíz que propicien su uso. Dosis de 1,5 $1 . \mathrm{t}^{-1} \mathrm{MF}$ provocan reducciones de 13,70,13,90,14,05, 19,61, 29,79 y $15,13 \%$ en el contenido de $\mathrm{NDT}_{1 \mathrm{X}}$, la energía digestible, metabolizable, neta de mantenimiento, neta de ganancia y neta de lactación, respectivamente. La aplicación del inóculo producido en finca en dosis de 0,5 $1 . \mathrm{t}^{-1} \mathrm{MF}$ podría ser factible, debido a que presenta resultados similares al inóculo comercial, lo cual disminuye los costos de producción del ensilajes con uso de aditivos de este tipo, con lo cual se logra una eficiencia mayor en el uso de los recursos en la finca.
El problema de los inóculos producidos en finca de forma artesanal empleados como aditivos para ensilajes, se debe a la ausencia de controles de calidad durante su elaboración que garanticen las poblaciones de microorganismos benéficos (Lactobacilos) para el proceso fermentativo. La caracterización del tipo de organismos y sus diferentes proporciones presentes en los inóculos elaborado en finca en el momento de su aplicación, es fundamental para evaluar el impacto que presenta sobre el proceso fermentativo del ensilaje de maíz.

La utilización de este tipo de biotecnologías es recomendable en otros forrajes verdes como las leguminosas o gramíneas tropicales, cuyo proceso fermentativo es más restringido, en donde su impacto a nivel fermentativo y nutricional sería de mayor relevancia.

\section{LITERATURA CITADA}

ABDELHADI L. 2007. Los silajes en la producción animal: importancia de la calidad, pp. 114-131. In: R. Trejos, C. Zambrano, W. García, C. Tobia, L. Mancilla, N. Valbuena, F. Ramírez (eds). Memorias XI Seminario Manejo y utilización de pastos y forrajes en sistemas de producción animal. UPEL, Barquisimeto, Venezuela.

AOAC. 1991. Association of Official Agricultural Chemist. Official methods. $11^{\text {th }}$ edition. Washington D.C., USA. 1015 pp.

BALLARD C., THOMAS E., TSANG D., MANDEBVU P. 2001. Effect of corn silage hybrid on dry matter yield, nutrient composition, in vitro digestion, intake by dairy heifers, and milk production by dairy cows. Journal Dairy Science 84(2):442-452.

BAXTER H., MONTGOMERY M., OWEN J. 1980. Digestibility and feeding value of corn silage fed with boot stage wheat silage and alfalfa silage. Journal Dairy Science 63(2):255-261.

BOSCHINI C., ELIZONDO J. 2003. Curso teórico y práctico de ensilaje de forrajes. Serie Agrotecnológica 1. Universidad de Costa Rica. Facultad de Ciencias Agroalimentarias. $16 \mathrm{pp}$.

CABRAL L., VALADARES S., DETMANN E., TILEMAHOS J., GOMES O., GONCALVES R., SALES E. 2002. Cinética ruminal das fracoes de 
carbohidratos, producao de gás, digestibilidade in vitro da materia seca e NDT estimado da silagem de milho com diferentes proporcoes de graos. Bras. Zootec. 31(6):2332-2339.

CHEN J., STOKES M., WALLACE C. 1994. Effects of enzyme-inoculant. Systems on preservation and nutritive value of haycrop and corn silages. Journal Dairy Science 77(2):501-512.

Di MARCO O., AELLO M., ARIAS S. 2005. Digestibility and ruminal digestión kinetics of corn silage. Arq. Bras. Med. Vet. Zootecnia 57(2):223-226.

DIESEL C., FRENZEL P., BONNECARRERE L., VILMAR G., PAUli G., DORNELES L., PEREZ D. 2007. Comparação entre os métodos químicos, in situ e in vitro para estimativa do valor nutritivo de silagens de milho. Ciência Rural 37(3):835-840. Mai-Jun.

EUN J., BEAUCHEMIN K., SCHULZE H. 2007. Use of exogenous fibrolytic enzymes to enhance in vitro fermentation of alfalfa hay and corn silage. Journal Dairy Science. 90(3):1440-1451.

FERREIRA G., MERTENS D. 2005. Chemical and physical characteristics of corn silages and their effects on in vitro disappearance. Journal Dairy Science 88(12):4414-4425.

FOROUZMAND M., GHORBANI G., ALIKHANI M. 2005. Influence of hybrid and maturity on the nutritional value of corn silage for lactating dairy cows. Pakistan Journal of Nutrition 4 (6):435-441.

GIGER-REVERDIN S., DUVAUX-PORTER C., SAUVANT C., MARTIN O., NUNES do PARADO I., MÜLLER R. 2002. Intrinsic buffering capacity of feeds. Animal Feed Science Technology. 96:83-102.

GONZÁLEZ J. 1988. Evaluación de la elaboración del ensilaje de maíz en cinco fincas del cantón de Alfaro Ruiz. Tesis de licenciatura, Universidad de Costa Rica, San José, Costa Rica. 50 pp.

HAG M., VETTER R., KENEALY M. 1982. Effects of silage additives on fermentation characteristics of corn silage and performance of feedlot heifers. Journal Diary Science 65(2):259-266.

HOFFMAN P. 2005. Ash content of forages. College of Agricultural \& Life Sciences. University of Winsconsin. USA. Focus on Forage 7(1). 2 p.

HOLLAND C., KEZAR W., QUADE Z. 1995. The pioneer forage manual. A nutritional guide. Pioneer Hi-Bred International, Inc. Des Moines, Iowa, U.S.A. 40 p.
HUFFMAN C., DUNCAN C. 1955. Comparison of silages made from field corn (Ohio M15) and silage corn (Eureka) for milk production. Department of Dairy and Agricultural Chemistry, Michigan State University. Article $N^{\circ} .1833$ 998-1005.

JASAITIS D., WOHLT J., EVANS J. 1987. Influence of feed ion content on buffering capacity of ruminant feedstuffs in vitro. Journal of Dairy Science 70(7):1391-1403.

JASTER E. 1995. Legum and grass silage preservation, pp. 91-115. In: K Moore, M. Peterson (eds). PostHarvest Physiology and Preservation of Forages. Crop Science Society of Agronomy and American Society of Agronomy. CSSA Special Publication 22. Madison, Wisconsin USA.

JOHNSON L., HARRISON J., DAVIDSON D., ROBUTTI J., SWIFT M. 2002. Corn silage management I: Effect of hybrid, maturity, and mechanical processing on chemical and physical characteristics. Journal of Dairy Science 85(4):833-853.

KLEINSCHMIT D., KUNG L. 2006. A meta-analysis of the effects of Lactobacillus buchneri on the fermentation and aerobic stability of corn and grass and small-grain silages. Journal of Dairy Science 89(10):4005-4013.

KUNG L., CHEN J., KRECK E., KINUTSEN K. 1993. Effect of microbial inoculants on the nutritive value of corn silage for lactating dairy cows. Journal of Dairy Science 76(12):3763-3770.

KUNG L., MOULDER B., MULROONEY C., TELLER R., SCHMIDT R. 2008. The effects of silage cutting height on the nutritive value of a normal corn silage hybrid compared with brown midrib corn silage fed to lactating cows. Journal Dairy Science 91(4):14511457.

LEÓN B., MONTENEGRO A. 2001. Sistema de cultivo de maíz asociado con soya para la elaboración de ensilaje. Tesis de licenciatura, Universidad de Costa Rica, San José, Costa Rica. 90 p.

LINN J. 2001. XVII. Curso de especialización: Necesidades nutritivas del Ganado vacuno lechero. Department of Animal Science. University of Minnesota. $24 \mathrm{pp}$.

LUTHER R. 1986. Effect of microbial inoculation of whole-plant corn silage on chemical characteristics, preservation and utilization by steers. Journal of Animal Science 63(1):1329-1336. 
MAHANNA W. 1993. Silage fermentation and additive use in North America. Silage production. From seed to animal. National production conference. Syracuse, New York. 95 pp.

MANCHIN D. 2001. El uso potencial del ensilaje en el trópico para la producción animal en la zona tropical, especialmente como una opción para los pequeños campesinos, pp. 81-86. In: L. Mannetje (eds). Uso del ensilaje en el trópico privilegiando opciones para pequeños campesinos. Serie Estudios FAO. Producción y protección vegetal 161. FAO, Roma. 189 p.

McDONALD P. 1981. The biochemistry of silage. John Wiley \& Sons. Chichester, University of Edinburgh. $226 \mathrm{pp}$.

MONTAÑEZ O., BARCENA R., GONZÁLEZ S., ORTEGA M., COBOS M., AVELLANEDA J. 2006. Evaluación de la capacidad amortiguadora de ingredientes utilizados en la formulación de dietas para rumiantes. Agronomía Mesoamericana. 17(1):7-10.

NEUMANN M., FRENZEL P., LAERTE J., RESTLE J., OST P. 2007. Efeito do tamanho de particular e da altura de colheita das plantas de milho (Zea mays L.) sobre as perdas durante o proceso fermentativo o período de utilizacao das silagens. Revista Brasileira de Zootecnia 36(5):1395-1405.

OTERO M., ESPERANCE M. 1994. Estudio de la sensibilidad de la Guinea Likoni (Panicum maximun Jacq) según el índice de azúcar/capacidad tampón. Pastos y forrajes (Cuba) 17(3):277-281.

PALMQUIST D., JENKINS T. 1980. Fat in lactation rations: Review. Journal of Dairy Science 63:1-14.

PEÑA P., Del POZO P. 1992. Explotaciones de pastos y forrajes. Tomo II. ISCAH. La Habana, Cuba. 249 p.

QUIRÓS G. 1992. Efecto de niveles crecientes de pseudotallo de banano en combinación con ensilajes de maíz, sobre el crecimiento de terneras Jersey en confinamiento. Tesis de licenciatura. Universidad de Costa Rica, Costa Rica. 75 p.

RANJIT N., KUNG L. 2000. The effect of Lactobacillus buchneri, Lactobacillus plantarum, or a chemical preservative on the fermentation and aerobic stability of corn silage. Journal of Dairy Science. 83(3):526-535.

ROJAS A. 1985. Effect of rolled corn silage on digestion of nutrients and feedlots performance of growing steers. Tesis de maestría. Iowa State University, Ames, Iowa, USA. 93 p.

SAS. 2003. SAS 9.1.3 for Windows. Service Pack 4. Win Pro plataforma. Copyright (c) 2002-2003 by SAS Institute Inc. Cary NC. USA.

SÁNCHEZ J.M., SOTO H. 1996. Estimación de la calidad nutricional de los forrajes del cantón de San Carlos. I. Materia seca y componentes celulares. Revista Nutrición Animal Tropical (Costa Rica) 3(1):3-18.

SHAVER S., ERDMAN R., VANDERSALL J. 1984. Effects of silage $\mathrm{pH}$ on voluntary intake of corn silage. Journal Dairy Science 67(9):2045-2049.

SIBANDA S., JINGURA J., TOPPS J. 1997. The effect of level of inclusion of de legume Desmodium uncinatun and de use of molasses or ground maize as aditives on the chemical composition of grass and maize-legume silages. Animal Feed Science Technology 68(1):295-305.

STEFANIE J., ELFERINK O., DRIEHUIS F., GOTTSCHAL J., SPOELSTRA S. 2001. Los procesos de fermentación del ensilaje y su manipulación, pp. 31-40. In: L. Mannetje (eds). Uso del ensilaje en el trópico privilegiando opciones para pequeños campesinos. Serie Estudios FAO. Producción y protección vegetal 161. FAO, Roma. 189 p.

TITTERTON M., BAREEBA F. 2001. Ensilaje de gramíneas y leguminosas en los Trópicos, pp. 53-56. In: L. Mannetje (eds). Uso del ensilaje en el trópico privilegiando opciones para pequeños campesinos. Serie Estudios FAO. Producción y protección vegetal 161. FAO, Roma. 189 p.

TOBÍA C., SEQUERA C., CIOFFI R., VILLALOBOS E., ESCOBAR O. 2007. Experiencias en la elaboración de silaje de maíz-soya en dos sistemas de producción bovina en Venezuela, pp. 78-87. In: R. Trejos, C. Zambrano, W. García, C. Tobía, L. Mancilla, N. Valbuena, F. Ramírez (eds). Memorias XI Seminario Manejo y utilización de pastos y forrajes en sistemas de producción animal. UPEL, Barquisimeto, Venezuela.

VAN SOEST P., ROBERTSON J. 1985. Analysis of forages and fibrous food: A laboratory manual for animal science. Cornell University, New York. 613 pp.

WEISS W. 1999. Silage for dairy cattle, pp 10. In: Curso de actualización en nutrición de ganado de leche. Asociación Americana de la Soya. Indiana Soybean Board, y United Soybean Board. Balsa de Atenas, Costa Rica. 
WINGCHING-JONES R. 2006. Evaluación del proceso de ensilaje de Arachis pintoí. Tesis de maestría. Universidad de Costa Rica, San José, Costa Rica. $65 \mathrm{p}$.
WOHLT J. 1989. Use of a silage inoculant to improve feeding stability and intake of a corn silage-grain diet. Journal Dairy Science 72(2):545-551. 